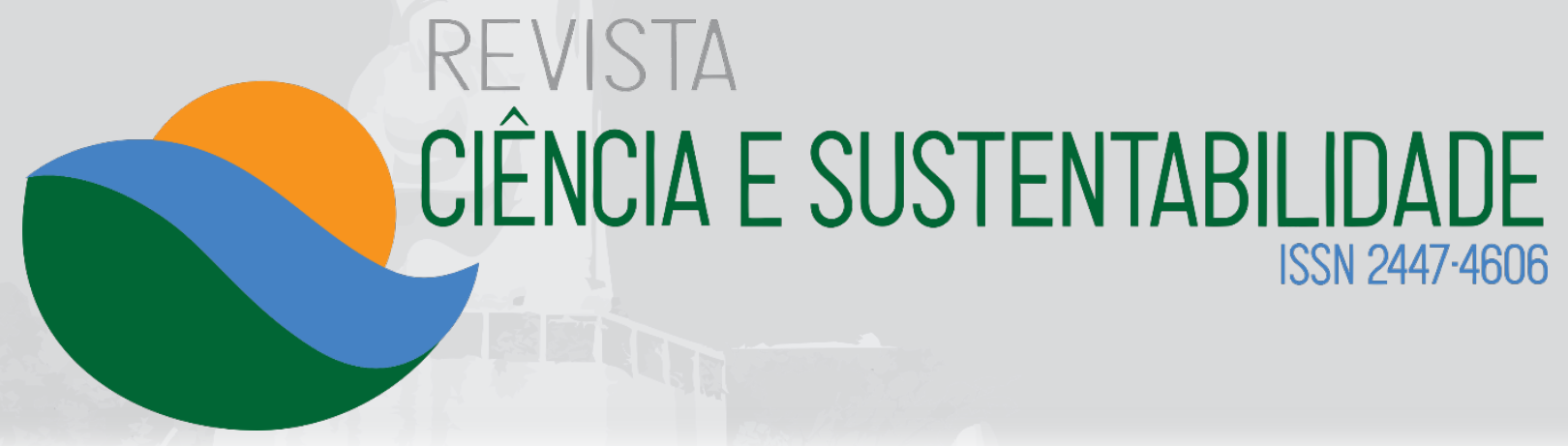

\title{
Perfil de consumo de água pelos moradores do município Crato-Ce
}

\section{Cristiano Cardoso Gomes \\ Universidade Federal Rural de Pernambuco (UFPRE) \\ Possui graduação em Licenciatura Plena em Ciências Agrícolas e Engenharia Florestal pela Universidade Federal Rural de Pernambuco (1999), e mestrado em Ciências Florestais pela Universidade Federal Rural de Pernambuco (2013). sustentavel@gmail.com}

\section{Francisco Lobo Tavares}

Sociedade Anônima de Água e Esgoto do Crato - SAAEC

Técnico em Contabilidade e Estatística sustentavel@gmail.com

\section{André Ramos de Souza}

Universidade Federal do Cariri (UFCA) Graduado em Engenharia Ambiental pelo Instituto Federal do Ceará e mestrando em Desenvolvimento Regional Sustentável (UFCA). Atualmente integra o quadro de funcionários da Sociedade Anônima de Água e Esgoto do Crato SAAEC.

engandresouza11@gmail.com

\begin{abstract}
Resumo
A população cratense possuí diferentes perfis de consumo de água, variando de acordo com a sua classe social, nível de escolaridade, hidrometração, entre outros fatores. Conhecer esses perfis é de grande relevância para a companhia de abastecimento, uma vez que embora o município possua uma boa oferta hídrica, a minimização de perdas e desperdício é uma necessidade cada vez mais emergente. A boa disponibilidade de água no município do Crato somada ao baixo preço cobrado e baixa hidrometração, construiu na população a crença de que esse recurso seria ilimitado. Compreender como essa água é consumida, pode colaborar em uma gestão mais eficiente. Para traçar o perfil foram realizadas visitas em 580 imóveis e realizadas entrevistas. As entrevistas demonstram que o consumo por banho é de 130,8 litros/dia/hab., a taxa de ocupação domiciliar é de 3,60 habitantes, a lavagem diária de louças acontece em média 2,4 vezes, resultando em um consumo $225,60 \mathrm{~L} / \mathrm{dia}$. A lavagem de roupa apresentou um consumo 1086,48 $\mathrm{L} / \mathrm{mês}$. Cerca de $10 \%$ dos consumidores requereram ampliar a oferta de água. Ao somar os diferentes tipos de consumo, o consumo total médio é de $31,69 \mathrm{~m}^{3} / \mathrm{mês} /$ consumidor, o que resultaria em um consumo de 293,42 $\mathrm{L} / \mathrm{hab} / \mathrm{dia}$. O consumo total é quase o dobro da média nacional e diante dos padrões de consumo, ficando evidente a importância da educação hidroambiental de forma a reduzir o desperdício.
\end{abstract}




\section{José Yarley de Brito Gonçalves}

Graduado em Geologia pela Universidade Federal de Pernambuco - Instituto de Geociências (1975) e Mestre em Desenvolvimento Regional Sustentável na Universidade Federal do Ceará - Campus Cariri. Atualmente é Diretor-presidente da Sociedade Anônima de Águas e Esgoto do Crato (SAAEC) e é vice-presidente da regional IV da Associação Nacional dos Serviços Municipais de Saneamento yarleybg@yahoo.com.br
Palavras-chave: Perfil de consumo de água.Tempo de banho. Tempo de lavagem.

\section{Abstract}

The cratense population has different profiles of water consumption, varying according to their social class, level of education, hydrometric, among other factors. Knowing these profiles is of great relevance for the supply company, since although the municipality has a good water supply, minimizing losses and waste is an increasingly emerging need. The good availability of water in the municipality of Crato added to the low price charged and low hydromassage, built in the population the belief that this resource would be unlimited. Understanding how this water is consumed can contribute to a more efficient management. To trace the profile were carried out visits in 580 real estate and conducted interviews. The interviews show that the consumption per bath is 130.8 liters / day / inhabitant, the household occupancy rate is 3.60 inhabitants, the daily washing of dishes is on average 2.4 times, resulting in a consumption of $225,60 \mathrm{~L} /$ day. The washing of laundry presented a consumption 1086,48 L / month. About $10 \%$ of consumers demanded to expand their water supply. When adding the different types of consumption, the average total consumption is $31.69 \mathrm{~m}^{3}$ / month / consumer, which would result in a consumption of $293.42 \mathrm{~L} /$ inhab / day. Total consumption is almost double the national average and consumption patterns, making clear the importance of hydro-environmental education in order to reduce waste.

Keywords: Water consumption profile. Bath time. Washing time. 


\section{INTRODUÇÃO}

A população cratense possuí diferentes perfis de consumo de água, variando de acordo com a sua classe social, nível de escolaridade, hidrometração, entre outros fatores. Conhecer esses perfis é de grande relevância para a companhia de abastecimento, uma vez que embora o município possua uma boa oferta hídrica, a minimização de perdas e desperdício é uma necessidade cada vez mais emergente. A condição de boa disponibilidade hídrica está relacionada com a situação geográfica do município do Crato (CE) na Chapada do Araripe.

A Chapada do Araripe localizada no sul do Ceará, Sedimentar do Araripe, favorece a ocorrência de morfogênese química, formando um típico brejo de encosta (SOUZA, 1988). Essas condições ambientais propiciam características peculiares as paisagens da região do Cariri Cearense, representadas por uma complexa rede de correlações entre feições geológicas, geomorfológicas, pedológicas, climáticas, hidrológicas e vegetacional. A Região do Cariri é conhecida como um "oásis" em meio ao sertão, devido as características geológicas da Chapada do Araripe, a precipitação que infiltra durante a época chuvosa, e que se recupera na forma de surgência na cota 750 m (GONÇALVES, 2001). Na extensão da chapada do Araripe no Estado do Ceará há um total de 325 fontes com uma vazão estimada de $1.645 \mathrm{~L} / \mathrm{s}$.

Um dos municípios de influência da chapada é a cidade do Crato, localizada no interior do Ceará, situado no sopé da Chapada do Araripe, extremo sul do Estado e na Microrregião do Cariri, e na chamada Região Metropolitana do Cariri. A boa disponibilidade de água no município do Crato somada ao baixo preço cobrado e baixa hidrometração, construiu na população do município o hábito do desperdício de água, e a crença de que esse recurso seria ilimitado (SOUZA, 2018).

A Região do Cariri tem nas águas subterrâneas da Bacia Sedimentar do Araripe a principal fonte de recursos hídricos necessário para seu desenvolvimento socioeconômico, dos 3.645 pontos d'água cadastrados, 252 são fontes naturais. Essas características refletem de forma cultural na população do município do Crato como uma região de água abundante e gratuita. Diante dessa problemática cultural, parte da população do município utilizam esse recurso de forma indisciplinada, elevando consideravelmente o consumo e consequentemente atingindo per captas bem superiores ao recomendado pela Organização Mundial de Saúde. 
A Organização Mundial de Saúde recomenda o consumo de água de $110 \mathrm{~L} /$ pessoa/dia para atender as necessidades de consumo e higiene. No Brasil, cada brasileiro consome em média, 156,7 L/pessoa/dia (BRASIL, 2019), o que representa quase 80 garrafas pet de 2 litros (RÁDIO AGÊNCIA, 2018).

Em 2018 o consumo médio dos consumidores hidrometrados de Crato foi de $156 \mathrm{~L} / \mathrm{dia}$, e os consumidores não hidrometrados (calculado por padrão de consumo) o consumo foi de $143 \mathrm{~L} /$ dia segundo dados da Sociedade Anônima de Água e Esgoto do Crato/CE (SAAEC). Apesar dos dados serem muito próximos da realidade brasileira, alguns bairros da cidade apresentam alto consumo e a captação é praticamente o dobro do que é regularmente faturado, decorrente de perdas no sistema e a não hidrometração de dois terços dos consumidores.

Dessa forma, compreender como essa água é consumida, pode colaborar na identificação de perdas e em uma gestão mais eficiente. Além disso, estabelecendo o perfil de consumo de água no município de Crato poderá auxiliar nas atividades do Programa de Educação Hidroambiental da SAAEC, criado em 2017 para promoção do uso racional de água.

Nessa perspectiva, Barreto (2008) destaca que o conhecimento da demanda de água possui grande influência sobre o gerenciamento do equilíbrio entre a retirada de água do meio ambiente e o abastecimento da mesma; além de moldar um perfil de hábito de consumo urbano de água. Por isso, é preciso diagnosticar o consumo de cada lugar em especial nas casas, já que, "o nível de demanda residencial varia consideravelmente de uma casa para outra dependendo de fatores socioeconômicos e características do imóvel" (MEMON; BUTLER, 2006).

Diante disto, o presente trabalho teve como objetivo conhecer o habito de consumidores de água da cidade, com recortes a rendimento familiar e localidade (bairro): i) o tempo de banho; ii) tempo de lavagem de roupa; iii) tempo de lavagem de louças v) tempo de lavagem de calçada.

\section{MATERIAL E MÉTODOS}

O município do Crato/CE possuí aproximadamente 130 mil habitantes e está situado ao sul do estado do Ceará (Figura 1), na região do Cariri e é considerado como um oásis no meio do sertão por conta das suas características geológicas e climáticas 
favoráveis a disponibilidade de água de excelente qualidade, o município dispõe de cerca de 36 mil ligações de água (SAAEC, 2019), divididas em 40 rotas/bairros.

Figura 1 - Localização do Município do Crato
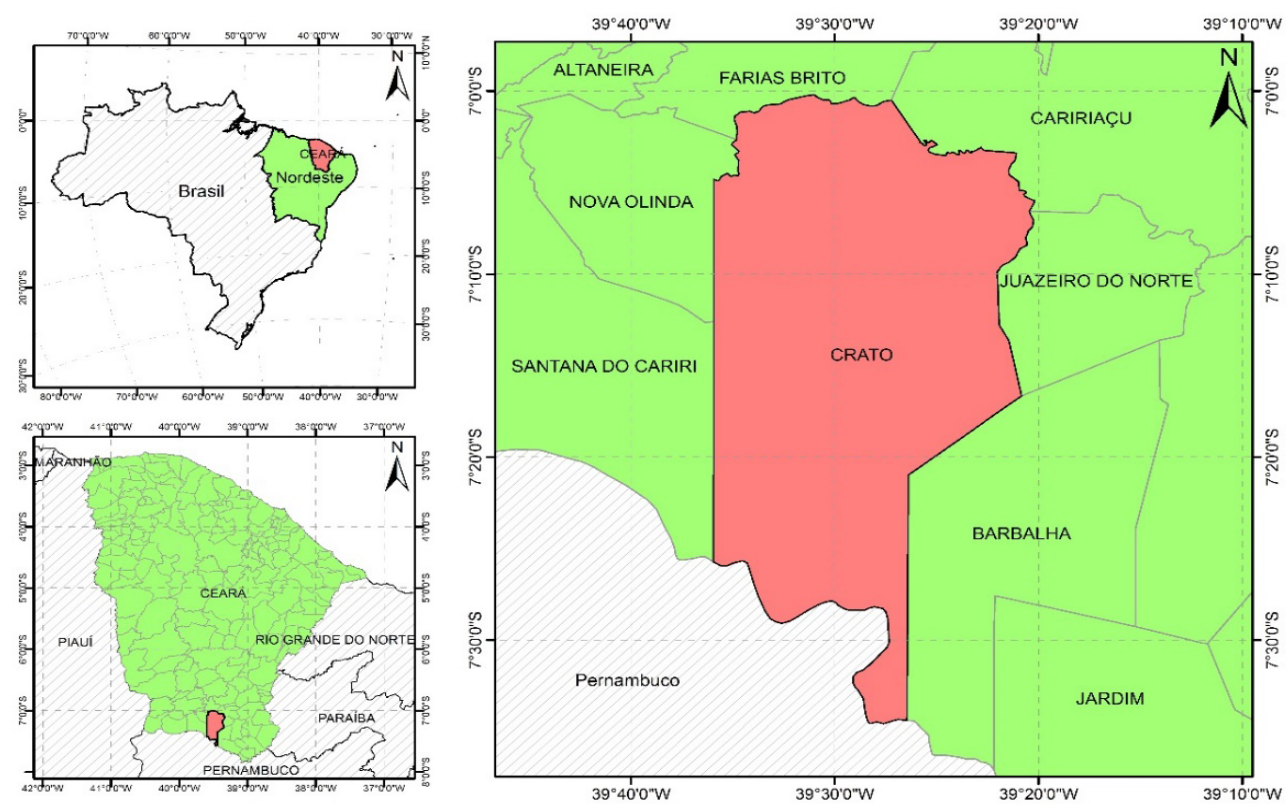

Da população total foram realizadas visitas em 580 imóveis e realizadas entrevistas sendo coletada localização geográfica dos mesmos. Para as entrevistas a equipe utilizou tablets para facilitar a sistematização dos dados aplicando questionário de acordo com os objetivos da pesquisa, através de pesquisadores treinados para abordagem específica. $O$ universo pesquisado foram pessoas residentes no município do Crato/CE com idade de 16 anos ou mais.

O método de amostragem foi aleatório simples. A amostra foi distribuída em cotas proporcionalmente ao tamanho de domicílios nos bairros sede e distritos. A margem de erro projetada foi de cinco pontos percentuais para o primeiro ano e quatro para o segundo ano, para mais ou para menos sobre os resultados encontrados no total da amostra, no limite do intervalo de confiança estimado em 95\% (noventa e cinco por cento). 
Ainda, em ambos os momentos foram filtrados $100 \%$ dos questionários e checados $20 \%$ para atestar a realização da entrevista e a fidedignidade dos dados apurados. $\mathrm{Na}$ avaliação positiva foram agregados os conceitos Ótimo e Bom, enquanto a negativa a soma dos conceitos Ruim e Péssimo. $O$ conceito regular não é aproveitado nessa análise.

\section{RESULTADOS E DISCUSSÃO}

O tempo médio de demora do cratense no banho é de 10,9 minutos, ou seja, mais que o dobro do tempo fixado pela Organização Mundial da Saúde para um uso sustentável da água, que é de 5 minutos. Os resultados mostram (figura 2) que entre os entrevistados, 3,3\% informaram demorar mais de 20 minutos, principalmente as mulheres; moradores do bairro Vila Lôbo (33,3\%), Mirandão (23,1\%), Gizélia Pinheiro $(21,4 \%)$; pessoas cuja atividade está ligada a Serviços $(7,7 \%)$, Donas de Casa $(5,6 \%)$ e Estudantes (5,3\%). Considerando o consumo de água de $12 \mathrm{~L} / \mathrm{min}$ de um chuveiro (ABNT, 1996), o consumo por banho/pessoa é 130,8 litros, e tendo esse estudo revelado uma taxa de ocupação média é de 3,60 pessoas, o consumo do banho por família é de 470,88 L/dia.

Figura 2 - Tempo médio (minutos) de banho informado por moradores do município do Crato/CE

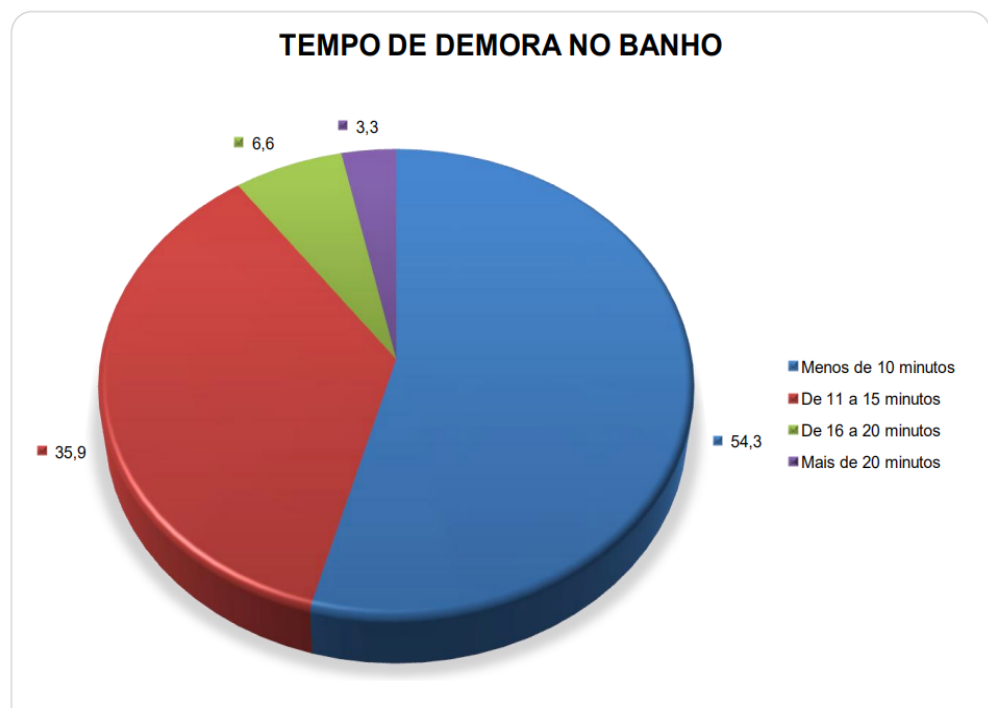


Entre os bairros de destaque tanto há bairros periféricos e de baixa renda como bairros de classe média alta, o que indica o uso ineficiente independe de classe socioeconômica, e mesmo educacional haja vista estudante figurarem entre os menos eficientes quanto ao uso de água.

Uma pesquisa realizada em 15 países evidenciou que os brasileiros, tomam em média 12 banhos/semana (LAGUARDIA, 2015), o que totalizam 48 banhos mensais. Dessa forma, o consumo de água total das famílias com banho seria de 22,622 $\mathrm{m}^{3 /}$ mês.

Em um estudo realizado por Ayres, Teixeira e Souza (2012) com estudantes da Universidade de Campinas - UNICAMP demonstrou que o tempo médio de banho de estudantes é de 14,6 minutos, o que evidencia que o tempo indicado nessa pesquisa não é distante de outras realidades.

Já a enquete aleatória realizada pelo portal Planeta Terra demonstrou que para $70 \%$ dos participantes o tempo médio de permanência no chuveiro é de 10 minutos. E 25\% levam 15 minutos, e apenas 3\% assumiram que seus banhos têm tempo superior a 15 minutos. O percentual dos que assumiram que tomam banhos longos $\mathrm{e}$ praticamente igual ao encontrado nessa pesquisa.

A figura 2 evidencia que $45,8 \%$ dos moradores do Crato, levam até 15 minutos com banho, sem fechar o registro, mais água do que o recomendado para todas as atividades de um dia inteiro. Um banho pode ser longo e ter baixo consumo desde que o consumidor mantenha o registro fechado.

O volume por banho de 130,8 L/banho é bem superior ao encontrado por Dalsenter (2016) potencial de economia de água potável por meio do aproveitamento de água pluvial em um condomínio residencial multifamiliar localizado em Florianópolis $-\mathrm{SC}$.

Sant'ana, Boeger e Vilela (2013) em estudo sobre Aproveitamento de águas pluviais e o reuso de águas cinzas em edifícios residenciais de Brasília - parte 1: reduções no consumo de água encontrou um tempo médio de banho de 9,2 minutos, inferior ao encontrado nesse estudo.

De acordo com a figura 3 a seguir, a maior parte dos entrevistados (52,2\%) afirmaram gastar entre 11 e 20 minutos na lavagem de louças. A frequência diária de lavagem de louças registrada pelos entrevistados foi em média de 2,4 vezes por residência, com o tempo médio de 15,6 minutos, gerando um consumo diário de 37,6 
minutos. Considerando um consumo de $6 \mathrm{~L} /$ minuto (ABNT, 2003) o consumo diário de água na lavagem de louças no município de Crato é de 225,60 L/dia, totalizando em um gasto de $6,77 \mathrm{~m}^{3} / \mathrm{mês}$.

Figura 3 - Tempo médio (minutos) de lavagem de louças por moradores do município do Crato/CE
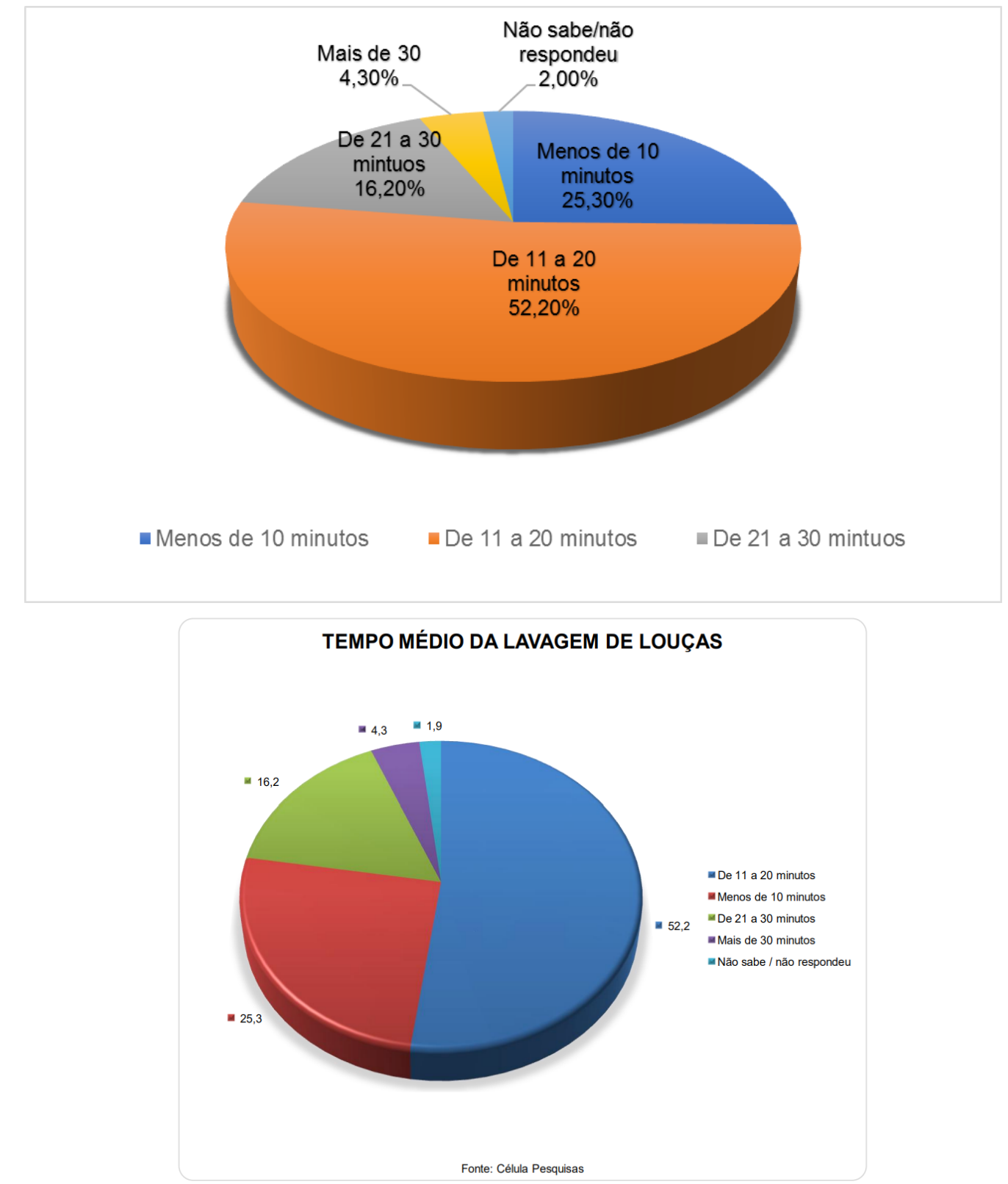
Ao dividir o consumo diário pela taxa de ocupação teríamos 62,66 L/pessoa $x$ dia que é superior ao valor de 50,50 L/pessoa $x$ dia encontrado na pesquisa de Dalsenter (2016) ao pesquisar potencial de economia de água potável por meio do aproveitamento de água pluvial em um condomínio residencial multifamiliar localizado em Florianópolis - SC.

Apenas $7,6 \%$ da população cratense não tem lavagem de roupa na própria residência, principalmente as pessoas cuja renda média mensal está acima de quatro salários mínimos (22,2\%). A frequência semanal de lavagem de roupa chega a 1,8 vezes por residência, com o tempo médio de 50 minutos de duração.

A Figura 4 evidencia-se que 29,7\% das pessoas passam mais de uma hora lavando roupas, e cerca de $65 \%$ levam mais de 30 minutos lavando roupas. A depender do estilo de lavagem, o consumo pode ser muito elevado. Considerando que $50 \%$ do tempo de lavagem a torneira esteja desligada, teríamos um consumo de 25,15 minutos. Para uma vazão de $6 \mathrm{~L} /$ minuto durante este tempo de lavagem de roupas, o gasto de água é de 150,9 L/lavagem, como a média é 1,8 lavagem/semana, em um mês tem-se entre os entrevistados uma frequência de 7,2 lavagem, gerando um consumo total mensal de água e $1,09 \mathrm{~m}^{3} / \mathrm{mês}$.

Figura 4 - Tempo médio (minutos) de lavagem de roupa por moradores do município do Crato/CE

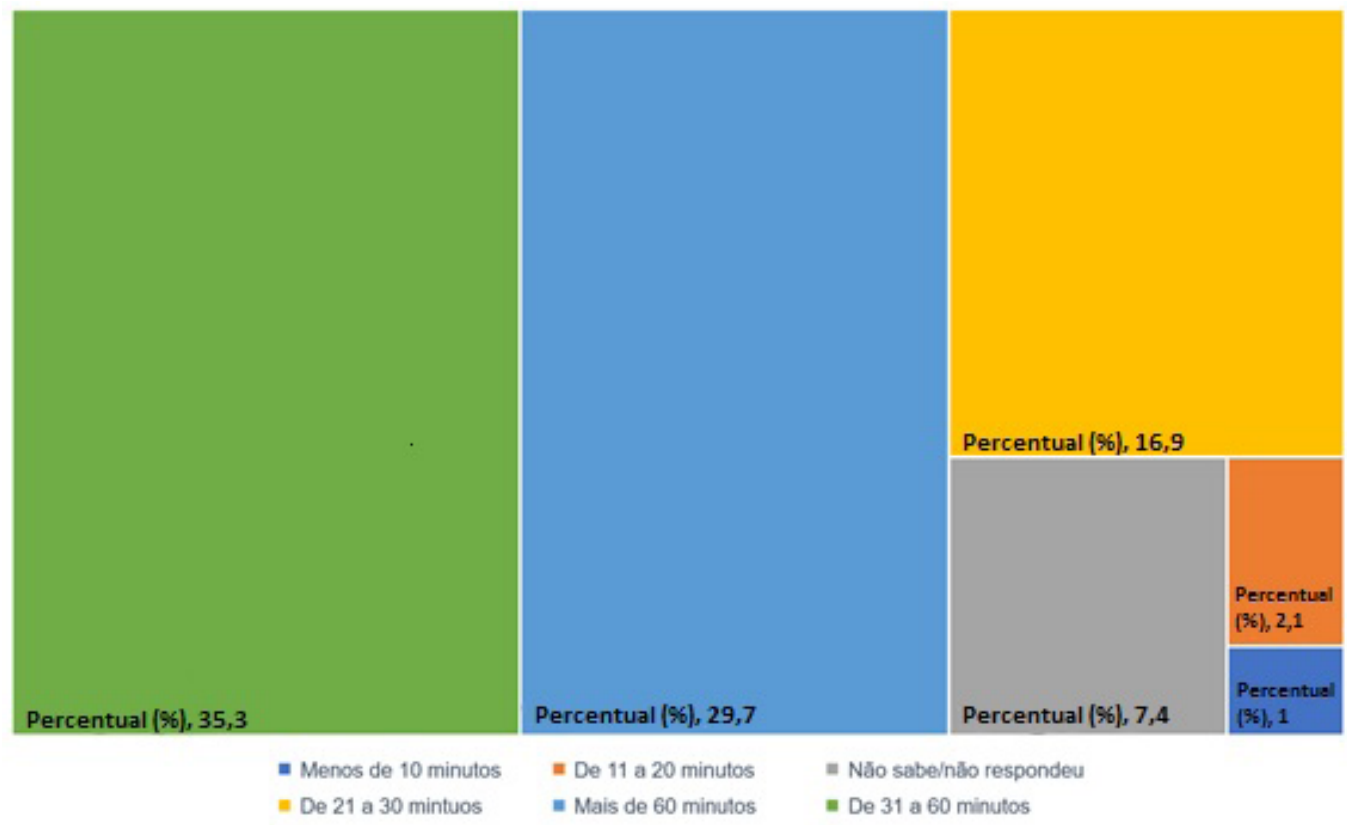


Dividindo o consumo de água mensal para a atividade por habitante temos o valor de 10,06 L/hab/dia que é menor ao valor $16 \mathrm{~L} / \mathrm{hab} / \mathrm{dia}$ determinado em estudo por Neves, Bértolo e Rossa (2006) em estudo de aproveitamento e reutilização da água para usos domésticos. Essa pesquisa indicou que 92,4\% disseram lavar roupa, e $41,4 \%$ dos entrevistados afirmaram lavar roupa mais de uma vez por semana enquanto $4,8 \%$ revelaram lavar roupa de 4 a 7 dias por semana. Mesmo considerando que uma parte da população dispões de lavadora de roupas o que reduz os indicadores de consumo, no Ceará uma pesquisa do IBGE indicou que apenas $33,34 \%$ dos lares tem lavadora de roupas (IBGE, 2019).

Cunha, 2013 ao realizar Caracterização e Monitoramento do Consumo de Água em Habitações De Interesse Social, verificou em monitoramento por ponto hidráulico que o maior gasto de água nestas residências ocorre na lavagem de roupas, com $41 \%$ do total de água consumida nas casas, que a média do consumo de água durante a semana não varia muito e que o dia de menor consumo é o domingo, assim mesmo que o número de lavagem não seja grande,

A Funasa (1991) estabelece em projetos o consumo mínimo de $2 \mathrm{~L} / \mathrm{hab} / \mathrm{dia}$ para beber e $6 \mathrm{~L} / \mathrm{hab} /$ dia para a cocção de alimentos, assim o consumo mínimo médio diário seria de $8 \mathrm{~L} / \mathrm{hab} /$ dia, como a taxa de ocupação é de 3,6 hab/imóvel, são necessários 28,8 L/dia mensalmente 864 L/residência.

Somando o consumo de banho, lavagem de roupa, lavagem de louça e consumo para cocção e beber, o consumo total de $31,34 \mathrm{~m}^{3} / \mathrm{mês} /$ consumidor (Tabela 1). O que resultaria em um consumo por habitante dia de 293,42 litros de água. O consumo determinado é quase 2 vezes a média nacional por habitante dia, que é 156,7 litros de água (BRASIL, 2019) e quase 3 vezes a recomendação de 110 litros/diário da Organização Mundial de Saúde.

Tabela 1 - Consumo de água por Atividade domiciliare

\begin{tabular}{|l|l|}
\hline Atividade & Consumo $\left(\mathrm{m}^{3} / \mathrm{mês}\right)$ \\
\hline Banho & 22,622 \\
\hline Lavagem de louça & 6,768 \\
\hline Lavagem de roupa & 1,086 \\
\hline Consumo e cocção de alimentos & 0,864 \\
\hline Total & $31,34$. \\
\hline
\end{tabular}


Segundo informações do setor técnico da SAAEC a captação média de água no município de Crato é de $29,16 \mathrm{~m} /$ consumidor, contudo há apenas o faturamento de cerca de $15 \mathrm{~m}^{3}$, influenciada tanto pela baixa hidrometração (um terço dos consumidores), como pelo alto número de ligações inativas (10\%), perdas na rede, ligações clandestinas e pela cultura de desperdício.

Os resultados dessa pesquisa demonstram que há uma diferença entre o que a empresa acredita captar e o consumo médio dos clientes, apesar de a diferença ser de 2,18 $\mathrm{m}^{3}$ /consumidor é sinal que há falha na estimativa de macromedição, outro aspecto relevante e que uso como lavagem de imóvel, carro, calçadas e irrigação não entraram no consumo domiciliar, o que certamente eleva o consumo médio, e efetiva a afirmação de que a empresa desconhece o volume real captado. Reforçado ainda pelo fato de que não existe sistema sem perdas, não poderia a captação ser igual ao uso. Sugere-se que a empresa reveja suas estimativas de captação, inicie a macromedição e que reforçada a educação hidroambiental, crie campanhas educativas, além de reforçar a hidrometração nos bairros com baixa eficiência no uso de água e dividir os bairros por sistema de abastecimento.

Considerando que nosso intervalo de confiança foi de $95 \%$ e erro é de 4 a $5 \%$, mesmo que esse seja considerado no volume consumido pelos clientes, Crato apresenta padrões extremamente elevado de outros sistemas nacionais de abastecimento, o que reforça a ideia da falta de conscientização da população quanto ao consumo de água.

Apenas pouco mais de $2 \%$ da população cratense tem o hábito de lavar calçadas, pátios e quintais diariamente (Figura 5), principalmente os moradores das seguintes localidades: Santa Rosa (33,3\%), Lameiro (14,3\%), Vila Alta (10,7\%), Vila Lobo e Zacarias Gonçalves (8,3\%) e São Miguel (6,1\%). Já a maioria faz isso raramente $(37,8 \%)$ ou nunca $(32,8 \%)$, não foi questionado o tempo de lavagem de forma a determinar o consumo. 
Figura 5 - Frequência de lavagem de calçadas, pátios e quintais

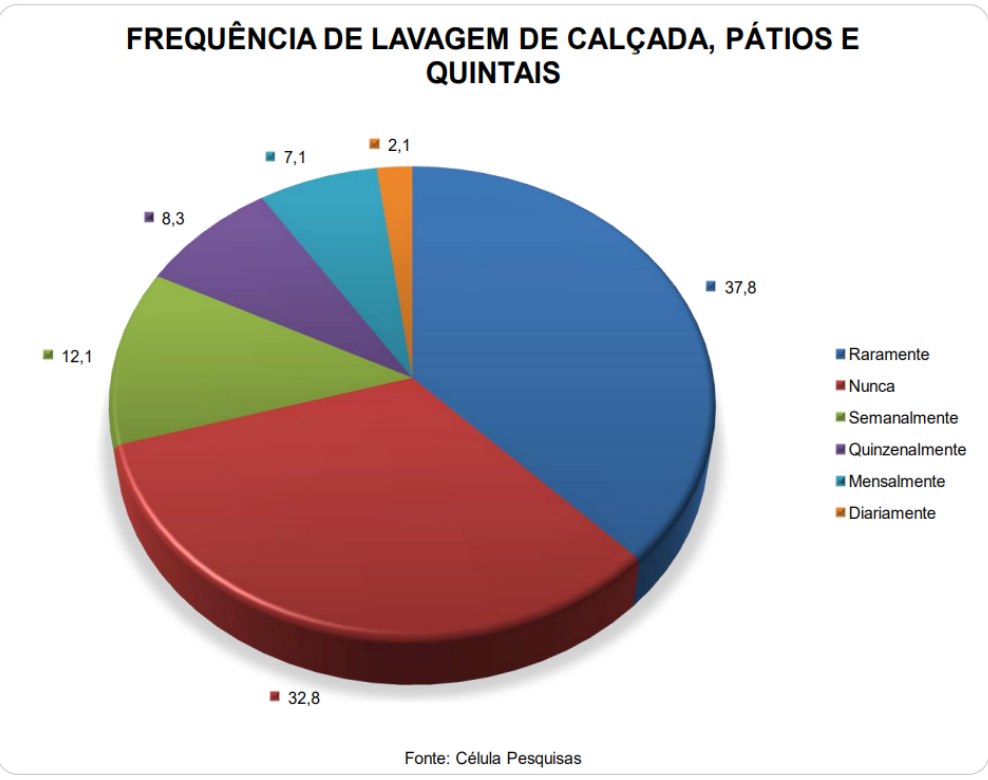

Dos bairros listados acima tantos há bairros onde a população de fonte de renda alta, média e baixa, o que demostra que a diferença econômica e mesmo social nos bairros não é fator para que haja o desperdício de água. Reuniões com associações de bairros, sensibilização de lideranças, fiscalização e ações diversas no bairro podem contribuir para reduzir a prática.

O bairro de Vila Alta é um dos bairros que, segundo a empresa de água, mais reclama de interrupções no abastecimento e qualidade de água, no entanto está entre os que usam água para lavagem de pisos diariamente. O principal problema relatado pela companhia de abastecimento do Crato para o bairro Vila Alta é a ausência de reservatórios na maior parte dos domicílio, com isso, sempre que ocorrem interrupções no sistema de abastecimento, seja por manutenção ou problemas técnicos, a população fica sem abastecimento até que o problema seja contornado.

Os dados permitirão a empresa a criar um ranking de consumo por localidade, e isso em muito ajuda as pessoas entenderem que não é apenas os grandes imóveis e bairro de classe alta que tem padrões ineficientes de uso de água, mas sim boa parte da cidade. É importante que os bairros com uso ineficiente sejam priorizados na hidrometração. 


\section{CONCLUSÃO}

Diante dos padrões de consumo informados, fica evidente que o consumo médio faturado pela empresa de água, está distante do real consumo dos consumidores, isso é fruto de que apenas um terço dos imóveis são hidrometrados (SAAEC, 2019), por outro lado, fica evidente a importância da educação hidroambiental de forma a reduzir o consumo de água.

Entender o perfil de consumo contribui para entender as localidades que necessitam de ação educacional ou mesmo de investimento para ampliação da oferta. No entanto, o que se percebe é que mesmo com a pegada hídrica dos moradores, cerca de $10 \%$ dos consumidores requereram ampliar a oferta de água, ficando mais evidente que os consumidores consideram a oferta de água ilimitada. É comum os usuários declararem que passam o dia fora de casa, mesmo assim o consumo de água ultrapassa a recomendação de 110 L/dia da Organização Mundial de Saúde.

\section{REFERÊNCIAS}

ASSOCIAÇÃO BRASILEIRA DE NORMAS TÉCNICAS. ANBR 5626: Instalação predial de água fria. Rio de Janeiro: ABNT, 1996. 41 p.

ASSOCIAÇÃO BRASILEIRA DE NORMAS TÉCNICAS. NBR 10281: Torneira de pressão: requisitos e métodos de. Rio de Janeiro: ABNT, 2003.

AYRES, A. O. C.; TEIXEIRA, D. C.; SOUZA, L. B. (2012). Estudo Sobre os Hábitos de Banho de Estudantes da Unicamp (Brasil) e do INSA-LYON (França). Revista Ciências do Ambiente On-line. v.8, n. 1, pp. 60-64.

BARRETO, D. (2008). Perfil do Consumo Residencial e Usos Finais da água.

Ambiente Construído. v. 8, n. 2, pp. $23-40$.

BRASIL. (2019). Secretaria Nacional de Saneamento. Ministério do Desenvolvimento Regional. Sistema Nacional de Informações sobre Saneamento: Diagnóstico 
dos Serviços de Água e Esgotos. Brasília: SNS/MDR, 2019. 226 p.

IBGE. Séries históricas \& Estatísticas: Domicílios particulares permanentes, por posse de máquina de lavar roupa. 2015. IBGE. Disponível em: https:// seriesestatisticas.ibge.gov.br/series.aspx?vcodigo=PD280. Acesso em: 18 maio 2019b.

CUNHA, K. F. (2013). Caracterização e Monitoramento do Consumo de Água em Habitações de Interesse Social. 2013. 93 f. Monografia (Especialização) - Curso de Bacharel em Engenharia Ambiental, Departamento de Engenharia Ambiental, Universidade Federal do Espírito Santo, Vitória, 2013.

DALSENTER, M. E. V. (2016). Estudo de potencial de economia de água potável por meio do aproveitamento de água pluvial em um condomínio residencial multifamiliar localizado em Florianópolis - SC. 2016. 74 f. TCC (Graduação) Curso de Engenheiro Civil., Departamento de Engenharia Civil, Universidade Federal de Santa Catarina, Florianópolis, 2016.

FUNASA - Fundação Nacional de Saúde (1991). Manual de Saneamento 2. ed. rev., Brasília. Fundação Nacional de Saúde, 408 p.

GONÇALVES, J. Y. B. (2001). A experiência do Cariri, no século passado de um sistema de gestão e alocação de água. Crato - CE. No prelo, 2001.

LAGUARDIA, I. (2019). Por que os brasileiros tomam tanto banho e os chineses tão pouco? 2015. El pais. Disponível em: https://brasil.elpais.com/brasil/2015/06/28/ internacional/1435483359_779060.html. Acesso em: 14 abr. 2019.

MEMON, F. A.; BUTLER, D. (2006). Water consumption trends and demand forecasting techniques. In: BUTLER, D.; ALI MEMON, F. (Ed.). Water demand management. London, UK: IWA Publishing, 2006. 361 p. ISBN 1-843390-78-7.

NEVES, M. V.; BERTOLO, E.; ROSSA, S. (2019). Aproveitamento e reutilização 
da água para usos domésticos. 2008. . Disponível em: https://paginas.fe.up. pt/ shrha/publicacoes/pdf/JHRHA_1as/RevistaHRHA6_AproveitamentoReutilizacao_ VERFINAL.pdf. Acesso em: 16 abr. 2019.

RÁDIOAGENCIA. Brasileiro consome cerca de 154 litros de água por dia; número é $\mathbf{4 0 \%}$ maior do que recomenda a OMS. 2018. Disponível em: http:// radioagencianacional.ebc.com.br/geral/audio/2018-02/brasileiro-consome-cerca-de154-litros-de-agua-por-dia-numero-e-40-maior-do-que. Acesso em 28 fev. 2019.

SAAEC. Relatório Resultado de Gestão 2018. Cristiano Cardoso Gomes (org.), Lya Tatiana de Almeida Ramos Gomes (org.). Disponível em: https://issuu.com/ saaeccrato/docs/saaec_-_resultados_gest_o_2018. Acesso em: 08 abr. 2019.

SANT'ANA, D.; BOEGER, L.; VILELA, L. (2013). Aproveitamento de águas pluviais e o reuso de águas cinzas em edifícios residenciais de Brasília - parte 1: reduções no consumo de água. Paranoá, Brasília, no 10, p. 77-84, 2013.

SOUZA, M.J.N. (1998). Contribuição ao estudo das unidades morfoestruturais do Estado do Ceará. Revista de Geologia (1): 73-91, junho, 1988.

SOUZA, A. R DE.; PAZ, E. B. A.; GOMES, C. C.; ALMEIDA, A. B. B. (2018). Ação Itinerante em Bairro Com Instrumento de Relacionamento ao Cliente e Recuperação De Perdas Financeiras. In: 48ª . Congresso Nacional da ASSEMAE. 2018, 1664-1671p. 